\title{
Novel Dithiolene Nickel Complex Catalysts for Electrochemical Hydrogen Evolution Reaction for Hydrogen Production in Nonaqueous and Aqueous Solutions
}

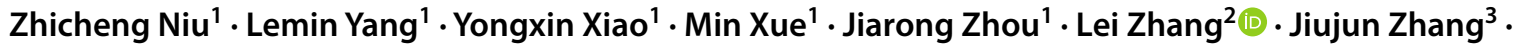 \\ David P. Wilkinson ${ }^{4}$. Chunlin $\mathrm{Ni}^{1}$
}

Accepted: 4 January 2022 / Published online: 20 January 2022

(C) The Author(s) 2022

\begin{abstract}
Three molecular catalysts based on mononuclear nickel(II) complexes with square planar geometries, $[\mathrm{BzPy}]_{2}\left[\mathrm{Ni}(\mathrm{mnt})_{2}\right]$ (1), $[\mathrm{BzPy}]_{2}\left[\mathrm{Ni}(\mathrm{i}-\mathrm{mnt})_{2}\right](\mathbf{2})$, and $[\mathrm{BzPy}]_{2}\left[\mathrm{Ni}(\mathrm{tdas})_{2}\right](\mathbf{3})(\mathrm{BzPy}=$ benzyl pyridinium $)$ are synthesized by the reaction of $\mathrm{NiCl}_{2} \cdot 6 \mathrm{H}_{2} \mathrm{O}$, [BzPy] Br, and $\mathrm{Na}_{2}(\mathrm{mnt}) / \mathrm{Na}_{2}(\mathrm{i}-\mathrm{mnt}) / \mathrm{Na}_{2}(\mathrm{tdas})(\mathrm{mnt}=1$,2-dicyanoethylene-1,2-dithiolate for (1), i-mnt $=2,2$-dicyanoethylene-1,1-dithiolate for (2), and tdas = 1,2,5-thiadiazole-3,4-dithiolate for (3)), respectively. The structures and compositions of these three catalysts are characterized by XRD, elemental analysis, FT-IR, and ESIMS. The electrochemical properties and the corresponding catalytic activities of these three catalysts are studied by cyclic voltammetry. The controlled-potential electrolysis with gas chromatography analysis confirms the hydrogen production with a turnover frequency (TOF) of $116.89,165.51$, and 189.16 moles of $\mathrm{H}_{2}$ per mole of catalyst per hour at a potential of $-0.99 \mathrm{~V}$ (versus SHE) in acetonitrile solutions containing the catalysts, respectively. In a neutral buffer solution, these three molecular catalysts exhibit a TOF of $411.85,488.76$, and $555.06 \mathrm{~mol}$ of $\mathrm{H}_{2}$ per mole of catalyst per hour at a potential of $-0.49 \mathrm{~V}$ (versus SHE), respectively, indicating that Complex 3 constitutes the better active catalyst than Complexes $\mathbf{1}$ and $\mathbf{2}$. For fundamental understanding, a catalytic HER mechanism is also proposed.
\end{abstract}

Keywords $\mathrm{Ni}(\mathrm{II})$ dithiolene complexes $\cdot$ Crystal structures $\cdot$ Electrocatalytic $\cdot$ Hydrogen evolution

\section{Introduction}

Hydrogen has been considered to be one of the most promising energy carriers due to its high energy density, environmental-friendly, and renewable and abundant

Lei Zhang

lei.zhang@nrc.gc.ca

$\triangle$ Chunlin Ni

niclchem@scau.edu.cn

1 College of Materials and Energy, South China Agricultural University, Guangzhou 510642, People's Republic of China

2 Energy, Mining and Environment, National Research Council of Canada, Vancouver, BC V6T 1W5, Canada

3 Institute for Sustainable Energy/College of Sciences, Shanghai University, 99 Shangda Road, Shanghai 200444, China

4 Department of Chemical and Biological Engineering, University of British Columbia, 2360 East Mall, Vancouver, BC V6T 1Z3, Canada production sources [1-3]. In general, there are many renewable ways for hydrogen production, such as solardriven, electro-driven, and thermal-driven water splitting. Electro-driven electrochemical water splitting is envisaged to be one of the simplest ways to generate hydrogen with high purity and has attracted great interest. In a water electrolysis device, some electrocatalysts have to be applied to speed up the oxygen evolution reaction (OER) at the anode and the hydrogen evolution reaction (HER) at the cathode. Particularly, for HER electrocatalysts, the traditional ones are platinum-based materials, which have been regarded as the best electrocatalysts for hydrogen evolution. However, the high cost and the limited resources of such precious materials have limited their large-scale practical application. Therefore, developing low-/non-Pt catalysts for water electrolysis have been given great efforts in the last several decades [4-10]. In the search of such low-cost and efficient electrocatalysts $[11,12]$, a number of new materials such as nickel [13-16], cobalt [17-20], and iron [21-23] complexes have been designed and synthesized. In recent 
years, a new class of dithiolene transition metal (nickel and copper) complexes with the crystal structures and magnetic properties have been explored for electrochemical energy applications [24-28]. In particular, the electrocatalytic activities of the nickel dithiolene complexes [29] and tetraphenylporphin cobalt complexes [30] have also been investigated in both the acetic acid and neutral buffer solution. Due to the special electronic property of dithiolene ligands, the electron density of these complexes are delocalized in metal-sulfur core, which benefits the electron storage [31]. The experiment results have demonstrated that such metal-dithiolene-based complexes could be applied as the efficient HER electrocatalysts for hydrogen production [32-35].

In this paper, three earth-abundant Ni-dithiolene complexes, $[\mathrm{BzPy}]_{2}\left[\mathrm{Ni}(\mathrm{i}-\mathrm{mnt})_{2}\right](\mathbf{1}),[\mathrm{BzPy}]_{2}\left[\mathrm{Ni}(\mathrm{mnt})_{2}\right](\mathbf{2})$, and $[\mathrm{BzPy}]_{2}\left[\mathrm{Ni}(\mathrm{tdas})_{2}\right](\mathbf{3}),\left(\mathrm{Bz}=\right.$ benzyl, Py $=$ pyridine, $\mathrm{mnt}^{2-}$ $=$ maleonitriledithiolate, $\mathrm{i}-\mathrm{mnt}^{2-}=2,2$-dicyanoethylene1,1-dithiolate, tdas $^{2-}=1,2,5$-thiadiazole-3,4-dithiolate), as shown in Fig. 1, have been chosen as the model systems to investigate their HER activities and the structure-activity relationship. The experiment results show that the dithiolene ligands play an important role in the HER activity of the complexes. Especially, the complex 3 ([BzPy $]_{2}\left[\mathrm{Ni}(\text { tdas })_{2}\right]$ ) can give a turnover number (TON) of 2202.2 at a potential of $-1.10 \mathrm{~V}$ (versus as $\mathrm{Ag} / \mathrm{AgCl}$ ) in $0.25 \mathrm{M}$ phosphate buffer solution and the catalytic HER activity can be kept for at least $48 \mathrm{~h}$.

\section{Experimental}

\section{Materials}

Benzyl bromide, pyridine, and $\mathrm{NiCl}_{2} \cdot 6 \mathrm{H}_{2} \mathrm{O}$ were purchased from Aldrich and were used without further purification. Sodium maleonitriledithiolate $\left(\mathrm{Na}_{2} \mathrm{mnt}\right)$, sodium 2,2-dicyanoethylene-1,1-dithiolate $\left(\mathrm{Na}_{2}(\mathrm{i}-\mathrm{mnt})\right)$, sodium 1,2,5-thiadiazole-3,4-dithiolate ( $\mathrm{Na}_{2}$ tdas), and benzyl pyridinium bromide [BzPy]Br were synthesized by following the literature procedures [36-39]. Tetrabutylammonium perchlorate $\left(\left[(\mathrm{n}-\mathrm{Bu})_{4} \mathrm{~N}\right] \mathrm{ClO}_{4}\right)$ was recrystallized from anhydrous ethanol and dried in vacuum oven.

\section{Syntheses of Complexes 1-3}

Synthesis of Complex 1 A solution of $\mathrm{Na}_{2}(\mathrm{mnt})$ ( $0.37 \mathrm{~g}$, $2 \mathrm{mmol})$ in methanol $(15 \mathrm{~mL})$ was added to a stirred solution of $\mathrm{NiCl}_{2} 6 \mathrm{H}_{2} \mathrm{O}(0.24 \mathrm{~g}, 1 \mathrm{mmol})$ in methanol $(15 \mathrm{~mL})$ to form a brown solution, which was filtered off and then added to a solution of [BzPy]Br $(0.51 \mathrm{~g}, 2$ $\mathrm{mmol})$ in methanol $(20 \mathrm{~mL})$. After stirring for $30 \mathrm{~min}$, a red precipitate was obtained, which was washed with methanol, filtered, and dried in a vacuum. The obtained red product was put in $\mathrm{MeCN} / \mathrm{i}-\mathrm{PrOH}(\mathrm{v} / \mathrm{v}=3: 1$ ), and the solvent was slowly evaporated in two weeks to obtain a red square crystal with a yield of $80 \%$. The obtained red crystal was analyzed with X-ray christallography with data analysis using the SHELXS program to obtain the molecular formula of $\mathrm{C}_{32} \mathrm{H}_{24} \mathrm{~N}_{6} \mathrm{NiS}_{4}$ with a structure as shown in Fig. 1a.

Complex 2 was synthesized following the steps of the preparation of Complex $\mathbf{1}$ by using $\mathrm{Na}_{2}(\mathrm{i}-\mathrm{mnt})$ instead of $\mathrm{Na}_{2}(\mathrm{mnt})$, and the brown sheet crystal was obtained with a yield of $82 \%$. The formula of $\mathrm{C}_{32} \mathrm{H}_{24} \mathrm{~N}_{6} \mathrm{NiS}_{4}$ with a structure shown in Fig. $1 b$.

Complex 3 was synthesized according to literature method [40], and the obtained formula is $\mathrm{C}_{28} \mathrm{H}_{24} \mathrm{~N}_{6} \mathrm{NiS}_{6}$ with a yield of $79 \%$, and a structure as shown in Fig. 1c.

\section{Crystal Structure Determination and Power X-ray Diffraction}

The single crystals of Complexes 1-3 were mounted on a Smart APEX CCD area detector, and data was collected using a graphite-monochromated Mo-K $\alpha$ radiation $(\lambda=0.71073 \AA)$ by $\varphi$ - $\omega$ scan mode at room temperature. Data were treated using a SAINT software program [41]. The structures were solved by a direct method using the SHELXS program [42, 43] and refined by the full-matrix leastsquares techniques (SHELXL) on $F^{2}$ [44]. The details of the crystallographic data, structure refinement, and data collection are summarized in Table S2, and selected bond lengths and angles are listed in Tables S3-S4. PXRD measurement was collected on a Rigaku-Ultima IV X-ray diffractometer using $\mathrm{Cu} K \alpha$
Fig. 1 Chemical structure of the anion: $\mathbf{a}\left[\mathrm{Ni}(\mathrm{mnt})_{2}\right]^{2-}(\mathbf{1})$, b $\left[\mathrm{Ni}(\mathrm{i}-\mathrm{mnt})_{2}\right]^{2-}(\mathbf{2})$, and $\mathbf{c}$ $\left[\mathrm{Ni}(\text { tdas })_{2}\right]^{2-}(\mathbf{3})$<smiles>C=C1S[N+]2(SC(C#N)=C(C#N)S2)SC(C#N)=C1C#N</smiles>

(a)<smiles></smiles>

(b)

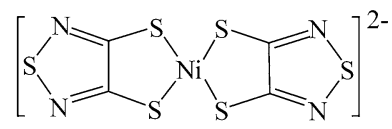

(c) 
radiation $(\lambda=1.5406 \AA$ ) in the angular range of $2 \theta=$ $5-50^{\circ}$ with a step size of $0.02^{\circ}$ and a fixed power source (40 kV, $40 \mathrm{~mA})$.

\section{Electrochemical Methods}

The cyclic voltammograms (CVs) were performed using a CHI 660E electrochemical analyzer under argon in a onecompartment three-electrode cell in which a glassy carbon was as the working electrode $(\Phi=1 \mathrm{~mm})$, a platinum as the counter electrode, a $\mathrm{Ag} / \mathrm{AgNO}_{3}\left(0.1 \mathrm{M} \mathrm{n}-\mathrm{Bu}_{4} \mathrm{NClO}_{4}\right.$ and $0.01 \mathrm{M} \mathrm{AgNO}_{3}$ in $\mathrm{MeCN}$ ) as the reference electrode for organic solution, and a $\mathrm{Ag} / \mathrm{AgCl}$ (saturated $\mathrm{KCl}$ solution) as the reference electrode for aqueous solution, respectively. The electrolyte was $0.1 \mathrm{M}\left[(\mathrm{n}-\mathrm{Bu})_{4} \mathrm{~N}\right] \mathrm{ClO}_{4}$ in $5 \mathrm{~mL} \mathrm{MeCN}$ (HPLC grade) containing $0.5 \mathrm{mM}$ catalyst. The ferrocene/ ferrocenium couple $(0.02 \mu \mathrm{M})$ was used as an internal standard. The working electrode was treated by polishing with $0.05 \mu \mathrm{m}$ alumina paste and then washed using deionized water.

\section{Controlled-Potential Electrolysis}

Bulk electrolysis was carried out in a two-compartment, gas-tight, H-type electrolysis cell, and the geometric surface area of the working electrode was $0.41 \mathrm{~cm}^{2}$. Homogeneous bulk electrolysis was performed the potential at $-0.99 \mathrm{~V}$ (versus SHE), with an solvent of $\mathrm{MeCN}(20 \mathrm{~mL})$ containing Complexes 1-3 $(1.0 \mathrm{mM})$ and $\left[(\mathrm{n}-\mathrm{Bu})_{4} \mathrm{~N} \mathrm{ClO}_{4}\right.$ as the electrolyte. Heterogeneous bulk electrolysis by holding the potential at $-0.49 \mathrm{~V}$ (versus SHE), with an solvent of 20 $\mathrm{mL}$ phosphate buffer solution $\left(0.1 \mathrm{M} \mathrm{KCl}, 0.25 \mathrm{M} \mathrm{KH}_{2} \mathrm{PO}_{4}\right.$ for $\mathrm{pH}$ 5.0) containing $10 \mu \mathrm{M}$ Complexes 1-3. The electrolyte was purged with dry gas containing $\mathrm{N}_{2} / \mathrm{CH}_{4}$ (v:v = 80: 20) for $20 \mathrm{~min}$. Chemical analysis of the headspace was performed by a FuLi 9790 Plus gas chromatograph equipped with argon as the carrier gas and also the thermal conductivity detector.

\section{Result and Discussion}

\section{Crystal Structures}

The reaction of nickel chloride, sodium dithiolene $\left(\mathrm{Na}_{2} \mathrm{mnt}, \mathrm{Na}_{2} \mathrm{i}-\mathrm{mnt}\right.$, or $\left.\mathrm{Na}_{2} \mathrm{tdas}\right)$ and benzyl pyridinium bromide in methanol at ambient conditions can result in three molecular catalysts (Complexes 1-3). The crystals of such three complexes can obtained by slow evaporation technique at room temperature in $\mathrm{MeCN}$ or $\mathrm{MeCN} / \mathrm{i}$ $\mathrm{PrOH}$, and the obtained products can be characterized by elemental analysis (Table S1), FT-IR (Figs. S1, S2 and S3), ESI-MS (Figs. S4, S5, S6 and S7), and X-ray single-crystal diffraction. These complexes can crystallize in the monoclinic space group $\mathrm{C} 2 / \mathrm{c}$ (Table S2) and consist of two " $\Lambda$-shaped" $[\mathrm{BzPy}]^{+}$cations and one bis(dithiolene)nickle(II) anion. The complexes show a symmetrical structure with the center nickle(II) anion and two symmetrical $[\mathrm{BzPy}]^{+}$cations situated each side (Fig. 2a-c). The $\left[\mathrm{Ni}(\mathrm{mnt})_{2}\right]^{2-},\left[\mathrm{Ni}(\mathrm{i}-\mathrm{mnt})_{2}\right]^{2-}$, and $\left[\mathrm{Ni}(\mathrm{tdas})_{2}\right]^{2-}$ moiety exhibits a square-planar configuration in which the $\mathrm{Ni}$ (II) ion is coordinated by four sulfur atoms from two dithiolene ligands. In the five-membered ring $\mathrm{NiS}_{4}$ of Complex $\mathbf{1}$, the average $\mathrm{Ni}-\mathrm{S}$ bond length is $2.171 \AA$ with an average $\mathrm{S}(1)-\mathrm{Ni}-\mathrm{S}(2)$ angle of $92.41(3)^{\circ}$. The $\mathrm{NiS}_{4}$ moiety of $\left[\mathrm{Ni}(\mathrm{i}-\mathrm{mnt})_{2}\right]^{2-}$ in Complex 2 is a four-membered ring with the corresponding Ni-S bond length of $2.204 \AA$ and S(1)-Ni-S(2) angle of 79.03(3) ${ }^{\circ}$. For Complex 3, the five-membered ring $\mathrm{NiS}_{4}$ of the $\left[\mathrm{Ni}(\text { tdas })_{2}\right]^{2-}$ anion is not completely planar, and two $\mathrm{S}$ atoms are deviated from the plane with the deviation values of $-0.015 \AA$ for $S(1)$ and $0.027 \AA$ for $S(2)$, respectively. The average Ni-S bond length is $2.197 \AA$ and the average angle of $\mathrm{S}(1)-\mathrm{Ni}-\mathrm{S}(2)$ was $93.20(3)^{\circ}$ [40].

PXRD was investigated to confirm the high purity of the crystals of Complexes 1-3 for further experiment. As shown in Figs. S8, S9 and S10, for Complex 1, the simulated XRD patterns with the diffraction peaks are located
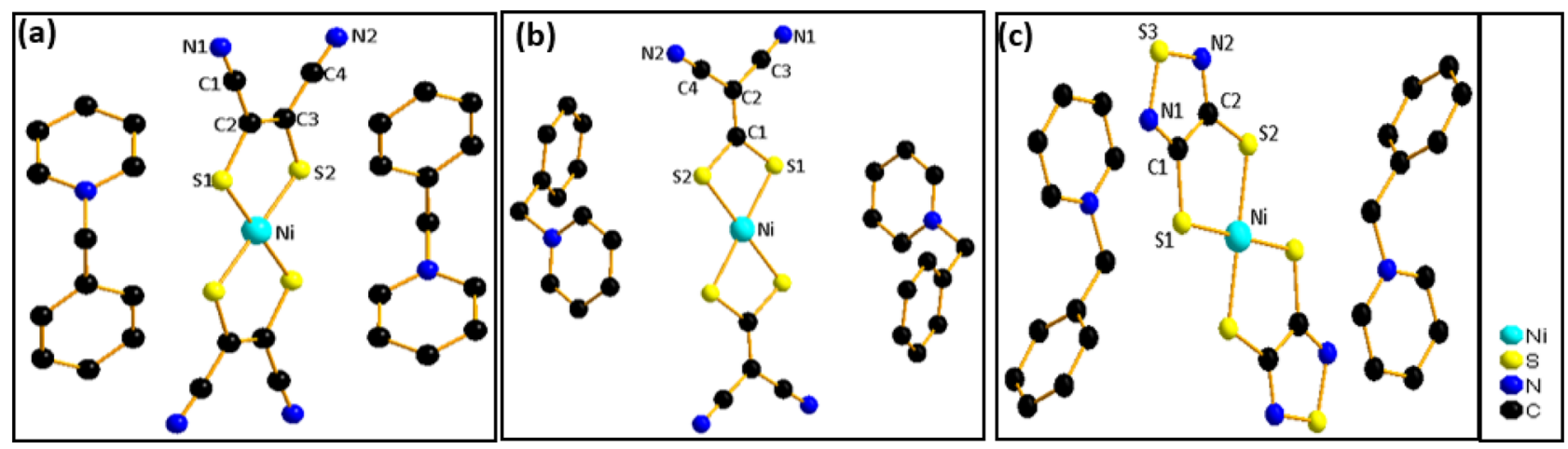

Fig. 2 Full molecular structure of Complex 1 (a), Complex 2 (b), and Complex 3 (c) shown at the 30\% probability level, and H atoms are omitted for clarity 
at $9.4^{\circ}, 9.9^{\circ}, 11.6^{\circ}, 13.8^{\circ}, 15.9^{\circ}, 17.3^{\circ}, 18.9^{\circ}, 19.7^{\circ}$, $20.5^{\circ}$, and $23.6^{\circ}$ can be attributed to the $\left(\begin{array}{lll}1 & 1 & 0\end{array}\right),\left(\begin{array}{lll}2 & 0 & -1\end{array}\right)$, (l $\left.0 \begin{array}{ll}0 & 2\end{array}\right),\left(\begin{array}{lll}1 & 1 & -2\end{array}\right),\left(\begin{array}{lll}1 & 1 & 2\end{array}\right),\left(\begin{array}{lll}0 & 0 & 3\end{array}\right),\left(\begin{array}{lll}2 & 2 & 0\end{array}\right),\left(\begin{array}{lll}0 & 0 & 2\end{array}\right),\left(\begin{array}{lll}2 & 2 & -2\end{array}\right)$, and $(2-3)$ crystal planes, respectively, which are corresponding to the experimental XRD patterns. For Complex 2, the simulated XRD patterns with the diffraction peaks are located at $9.4^{\circ}, 9.7^{\circ}, 11.8^{\circ}, 16.1^{\circ}, 17.5^{\circ}, 18.7^{\circ}, 19.9^{\circ}$, $20.3^{\circ}, 23.9^{\circ}$, and $26.6^{\circ}$ were ascribed to the $(20-2),(20$

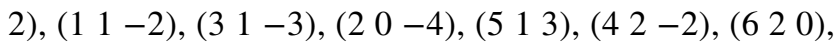
and $(40-6)$ crystal planes, respectively, which are corresponding to the experimental XRD patterns. For Complex 3 , the simulated XRD patterns with the diffraction peaks are located at $9.0^{\circ}, 9.8^{\circ}, 13.8^{\circ}, 15.5^{\circ}, 16.3^{\circ}, 18.2^{\circ}, 21.9^{\circ}$, $25.9^{\circ}, 27.6$, and $28.0^{\circ}$ were ascribed to the ( $\left.\begin{array}{lll}2 & 0 & 0\end{array}\right),\left(\begin{array}{ll}0 & 0\end{array}\right)$,

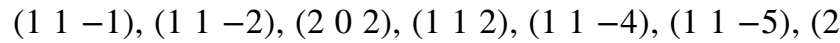
$2-2)$, and $\left(\begin{array}{lll}0 & 2 & 2\end{array}\right)$ crystal planes, respectively, which are corresponding to the experimental XRD patterns. Therefore, the experimental XRD patterns for Complexes 1-3 are consistent with the simulated XRD patterns on the basis of the single-crystal structure, confirming the high purity of the as prepared complexes.

\section{Cyclic Voltammetry Studies}

The electrochemical behavior of the three Ni(II) complexes and the corresponding cations were examined by cyclic voltammetry in $\mathrm{MeCN}$ with $\left[(\mathrm{n}-\mathrm{Bu})_{4} \mathrm{~N}\right] \mathrm{ClO}_{4}$ as the supporting electrolyte (Fig. 3a-d). The cyclic

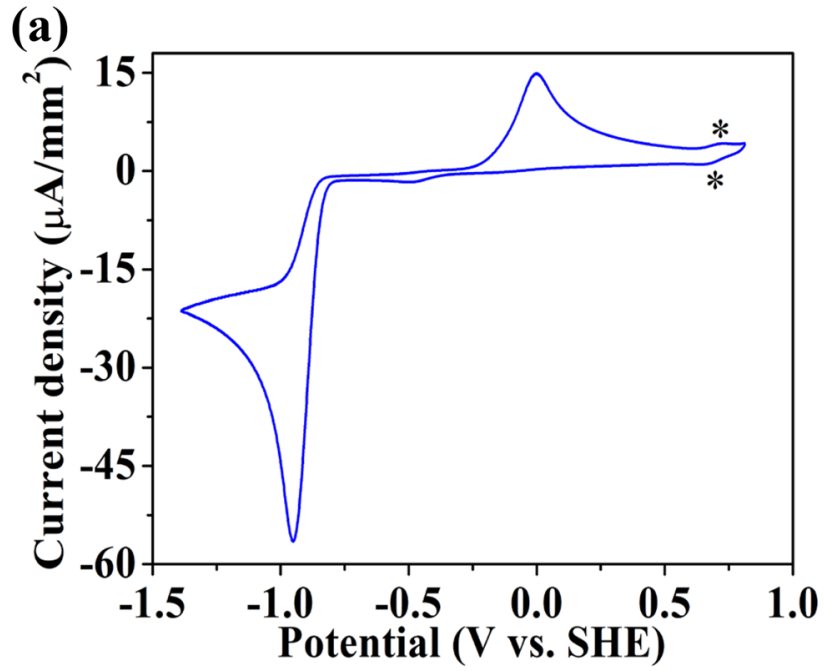

(b)

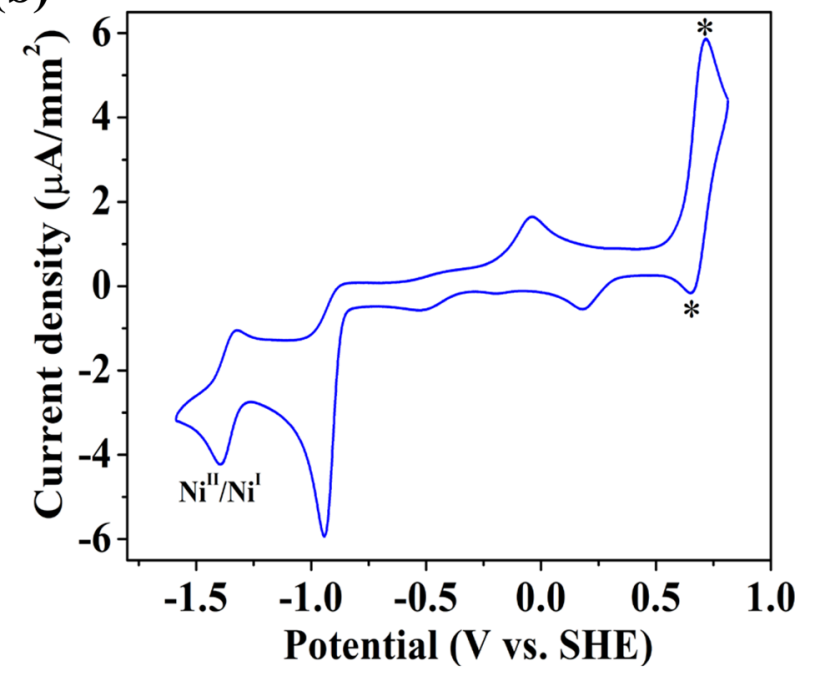

Fig. 3 Cyclic voltammograms of a cation $[\mathrm{BzPy}]^{+}$, b Complex 1, c Complex 2, and d Complex $3(0.5 \mathrm{mM})$ in $5 \mathrm{~mL} \mathrm{MeCN}$ with $0.1 \mathrm{M}$ $\mathrm{n}-\mathrm{Bu}_{4} \mathrm{NClO}_{4}$. Conditions: glass-carbon working electrode $(\phi=$ (b)

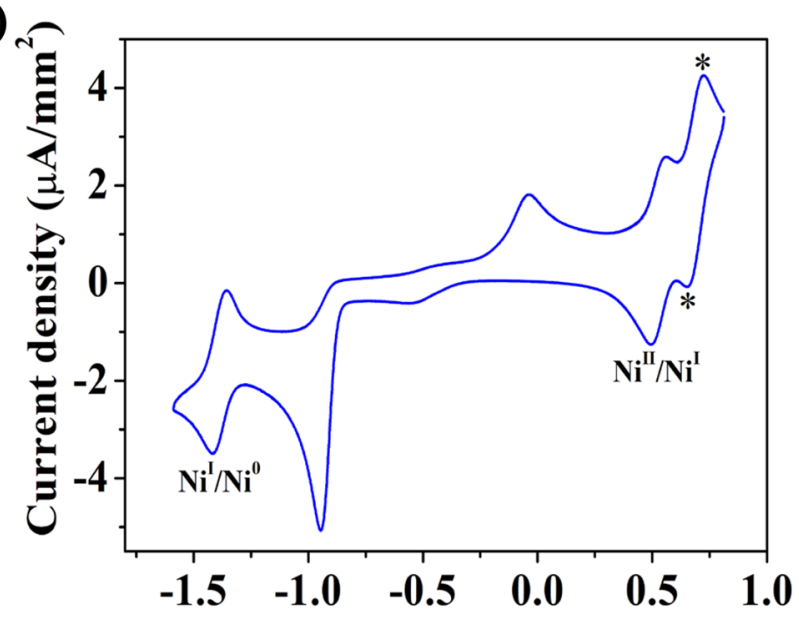

(d)

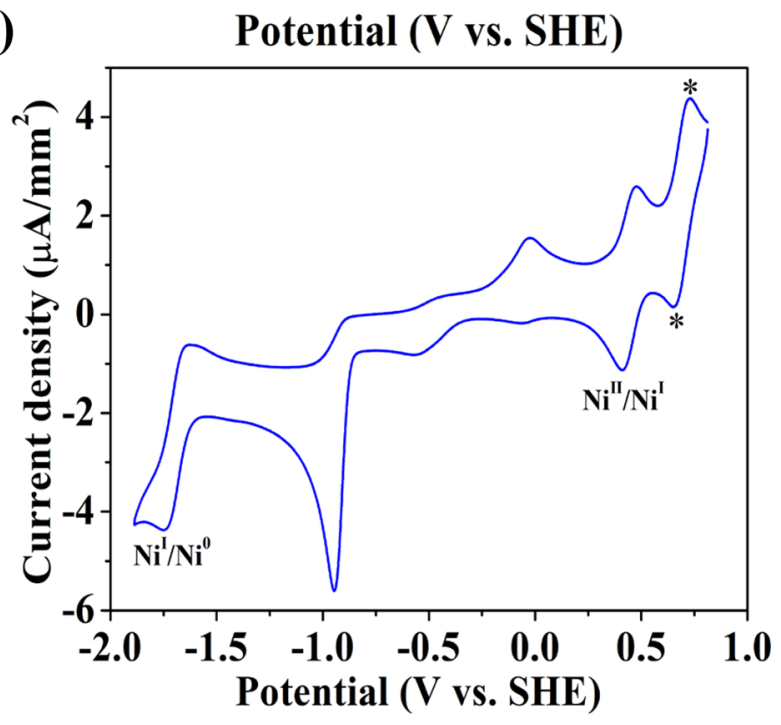

$1 \mathrm{~mm})$; Pt wire counter electrode; $\mathrm{Ag} / \mathrm{AgNO}_{3}$ pseudoreference electrode; ferrocene as the internal standard, scan rate $0.1 \mathrm{~V} \mathrm{~s}^{-1}, \mathrm{Fc}$ internal standard (*) 
Table 1 Peak data and reduction potential

\begin{tabular}{lllll}
\hline Complex & $\mathrm{E}_{\mathrm{pc} 1}\left(\mathrm{~V} \mathrm{vs} \mathrm{Fc}^{+} / \mathrm{Fc}\right)$ & $\Delta \mathrm{Ep}$ & $\mathrm{E}_{\mathrm{pc} 2}\left(\mathrm{~V} \mathrm{vs} \mathrm{Fc}^{+} / \mathrm{Fc}\right)$ & $\Delta \mathrm{Ep}$ \\
\hline 1 & $-0.12 /-0.05$ & 66 & $-2.03 /-1.97$ & 58 \\
2 & - & - & $-2.01 /-1.94$ & 60 \\
3 & $-0.20 /-0.13$ & 69 & $-2.36 /-2.24$ & 118 \\
\hline
\end{tabular}

$\mathrm{E}_{\mathrm{pc1}}$ is the first reduction peak, $\mathrm{E}_{\mathrm{pc} 2}$ is the second reduction peak

voltammograms $(\mathrm{CVs})$ of $[\mathrm{BzPy}]^{+}$cation reveals a reduction wave at $-0.95 \mathrm{~V}\left(\mathrm{~N}^{+/ 0}\right)$ and a oxidation wave at 0.002 $\mathrm{V}\left(\mathrm{N}^{0 /+}\right)$ vs SHE; Complex 1 shows a two-electron reversible reduction waves at $0.49 \mathrm{~V}(\Delta \mathrm{Ep}=66 \mathrm{mV})$ and -1.42 $\mathrm{V}(\Delta \mathrm{Ep}=58 \mathrm{mV})$; Complex 2 only exhibits a one-electron reversible reduction wave at $-1.40 \mathrm{~V}(\Delta \mathrm{Ep}=60 \mathrm{mV})$, and Complex 3 displays a one-electron reversible reduction wave at $-0.41 \mathrm{~V}(\Delta \mathrm{Ep}=69 \mathrm{mV})$ and an irreversible reduction wave at $-1.75 \mathrm{~V}(\Delta \mathrm{Ep}=118 \mathrm{mV})$ (Table 1). The first reduction wave could be assigned to the $\mathrm{Ni}^{\mathrm{II}} /$ $\mathrm{Ni}^{\mathrm{I}}$ process and the second one could be $\mathrm{Ni}^{\mathrm{I}} / \mathrm{Ni}^{0}$ process. Furthermore, as observed in Fig. 4a-f, the plots of peak current $\left(i_{p}\right)$ of the three complexes versus the square root of scan rate show the linear correlations, indicating that the diffusion-controlled process with the electrochemically active species freely diffusing in the solution and possible usage as the electrocatalysts of these three complexes for hydrogen evolution.

Furthermore, we have explored the catalytic behavior of the three complexes in phosphate buffer solution $(\mathrm{pH}$ 5.0). As shown in Figs. S11, S12 and S13, the electrode without catalyst in the solution can only give a weak current at $-1.10 \mathrm{~V}$, but with the addition of the catalyst, the peak current is increased obviously. In particular, the Complex 3 can give the highest catalytic current $(20.39 \mu \mathrm{A})$ in the same conditions.

\section{Effect of Acid Concentrations on Redox Potentials}

In order to investigate the impact of proton on the catalytic HER activity by the three complexes, we examined the change of $\mathrm{CVs}$ with increasing the concentration of acetic acid $\left(\mathrm{AcOH}, \mathrm{pK}_{\mathrm{a}}=22.3\right.$ in $\left.\mathrm{MeCN}\right)[45,46]$. As shown in Fig. $5 \mathrm{a}-\mathrm{c}$, the HER currents catalyzed by the three complexes are increased fast when the concentration of acetic acid is increased from 0 up to $0.17 \mathrm{M}$. The maximum peak current $\left(\mathrm{i}_{\text {cat }}\right)$ can be used to calculate the catalytic rate constant $\left(\mathrm{k}_{\text {obs }}\right)$ [47-49] and to value the electro-catalytic activity according to Eq. $1[24,26]$ where $i_{c a t}$ is the catalytic current, $i_{p}$ is the peak current without adding $\mathrm{AcOH}, n$ is the number of electrons in the reaction, $R$ is the ideal gas constant, $T$ is the temperature, $F$ is the Faraday's constant, and $v$ is the scan rate. $\frac{\mathrm{i} c a t}{i p}=\frac{n}{0.446} \sqrt{\frac{R T k o b s}{F v}}$

At the highest acid concentration $(0.17 \mathrm{M})$, values of $\mathrm{i}_{\text {cat }} /$ $\mathrm{i}_{\mathrm{p}}$ for Complexes 1, 2, and $\mathbf{3}$ are 134.9, 132.9 and 520.1 calculated from Eq. 1, which are coincided with the acidindependent turnover frequencies of $3529.3 \mathrm{~s}^{-1}, 3425.6 \mathrm{~s}^{-1}$, and $52476.0 \mathrm{~s}^{-1}$ with an overpotential of $388.1 \mathrm{mV}, 344.1$ $\mathrm{mV}$, and $520.1 \mathrm{mV}$, respectively (Tables S5, S6 and S7). In addition, it can be found that the $i_{c a l} / i_{p}$ values of the three complexes are increased linearly with increasing the concentration of $\mathrm{AcOH}$ (Fig. 6). Even at high acid concentrations, the values of $\mathrm{i}_{\mathrm{cat}} / \mathrm{i}_{\mathrm{p}}$ vs $[\mathrm{AcOH}]$ are still linearly changed with $\mathrm{AcOH}$ concentration, showing that the three complex catalysts can keep stable electrocatalytic activity in higher concentration of acid [14]. In particular, the turnover frequencies of Complex $\mathbf{3}$ is 15 times larger than those of Complexes $\mathbf{1}$ and $\mathbf{2}$, indicating the ligand of $\operatorname{tdas}^{2-}$ possesses an excellent electron storage ability [31].

Normally, the overpotential $(\eta)$ can reflect the activity of electro-catalyst; low $\eta$ value and high TOF (the turnover frequency) can result in better electrocatalytic activity [5, 50], the details calculation of $\eta$ and TOF were displayed in supplementary information (Fig. S18). The $\eta$ values of the three complex catalysts are decreased distinctly with increasing the concentration of AcOH (Tables S5, S6 and S7), indicating that the catalysts have high protonreduction abilities toward hydrogen even in weak acid conditions.

\section{Electrocatalytic Hydrogen Production in Acetonitrile and Water}

To further validate the catalytic activity of the as-prepared complex materials, electrocatalytic hydrogen production was estimated by bulk electrolysis. Processes of hydrogen production in homogeneous bulk electrolysis for three complex catalysts in $\mathrm{MeCN}$ are shown in Fig. 7a, b. It can be seen that during $4 \mathrm{~h}$ of bulk electrolysis, when 15.6, 17.3, and 20.8 Coulomb chargers are passed through the working electrode in three electrolyte solutions containing three different catalysts $167.2,195.3$, and $236.0 \mu \mathrm{mol}$ of hydrogen can be produced, respectively. The corresponding TON values are $794.8,1125.4$, and 1286.3 , and the TOF values are 198.6, 281.4, and $321.6 \mathrm{~h}^{-1}$ (Table S8), respectively. However, only $121.4 \mu \mathrm{mol}$ of hydrogen can be formed in bulk electrolysis without a catalyst at $4 \mathrm{~h}$ of reaction time.

The processes of hydrogen production in heterogeneous bulk electrolysis for complex catalyst-containing three phosphate buffer solutions are shown in Fig. 8a, b. After 4 h of 
(a)

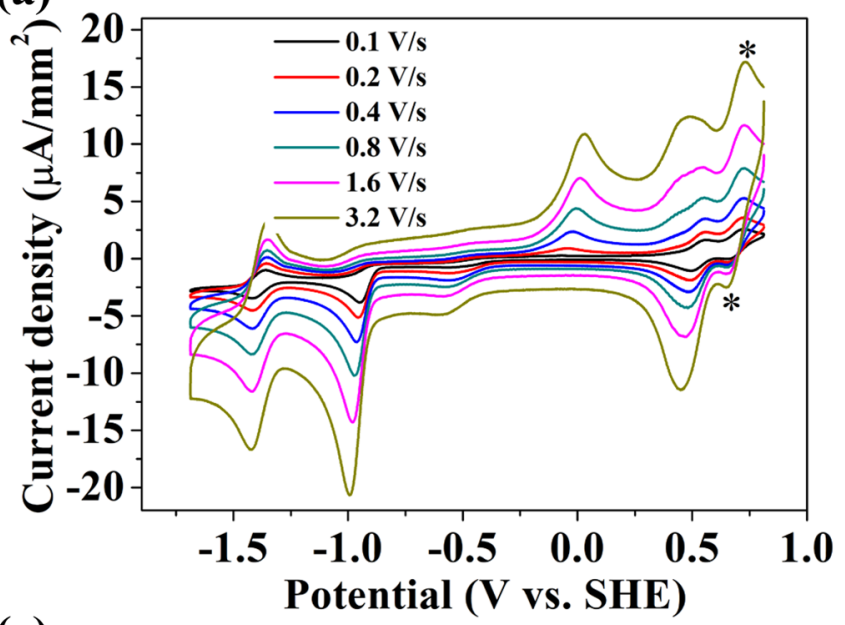

(c)

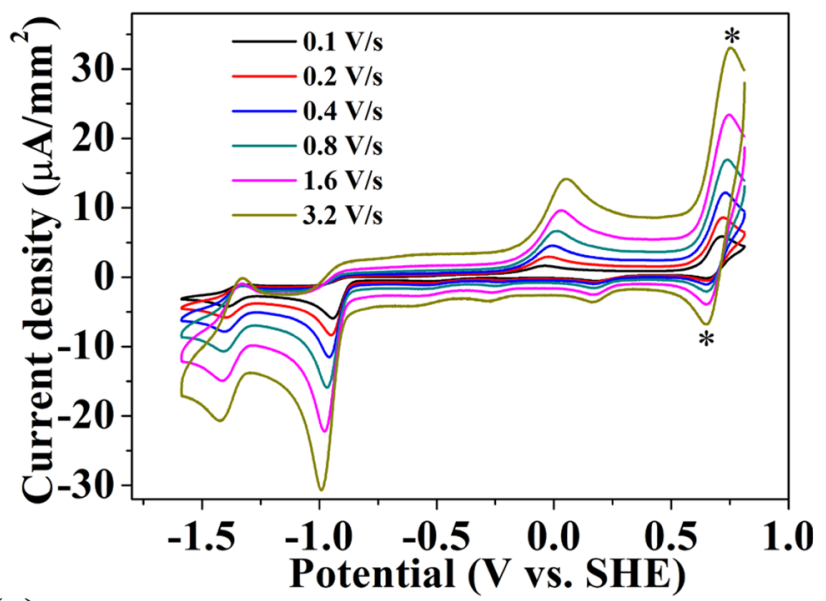

(e)

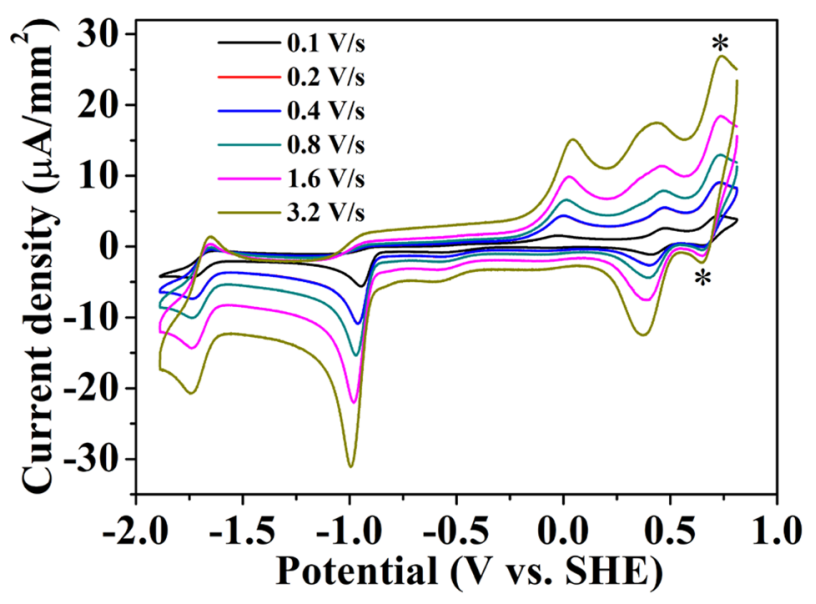

Fig. 4 Cyclic voltammograms of $0.5 \mathrm{mM}$ Complex 1 (a), Complex 2 (b), and Complex $\mathbf{3}$ (c) with variable scan rates and plots of $i_{p}$ vs scan rate for the second peak current of Complex 1 (d), Complex 2 (e),

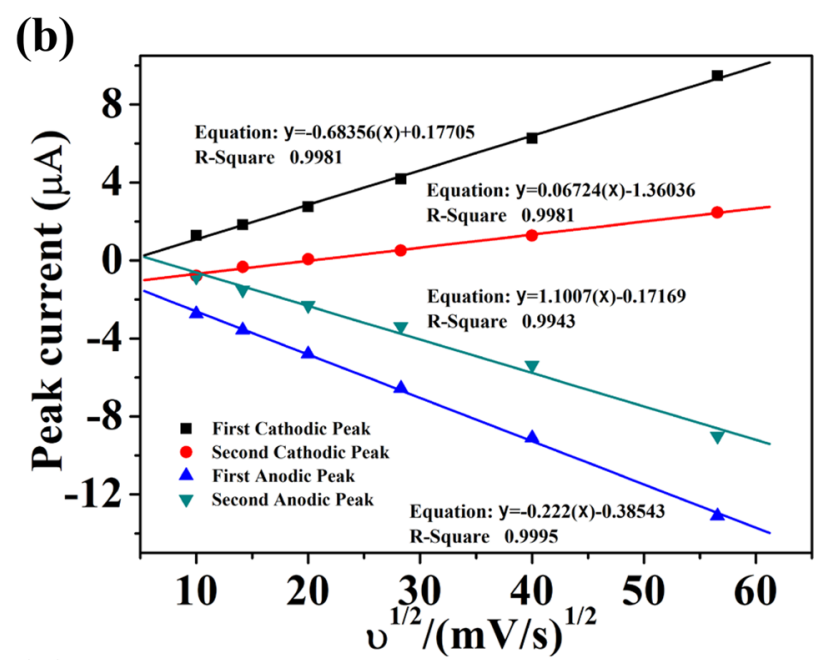

(d)

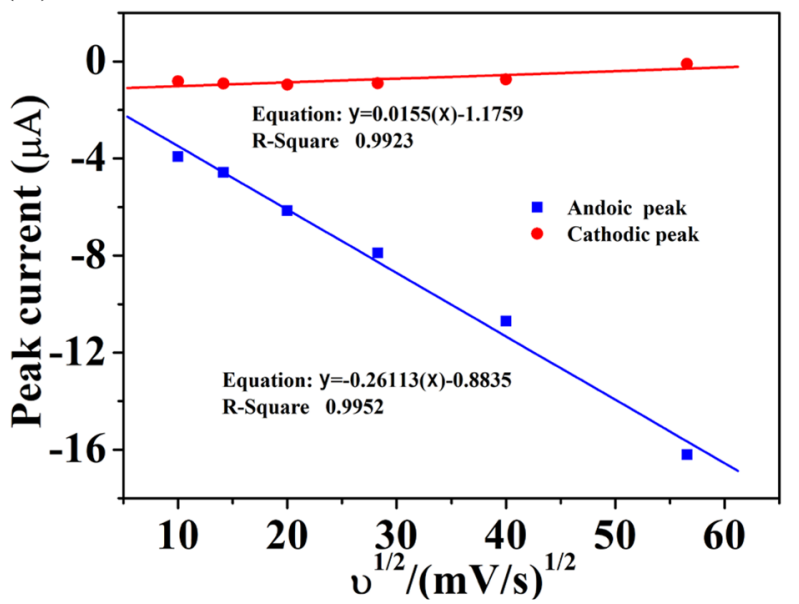

(f)

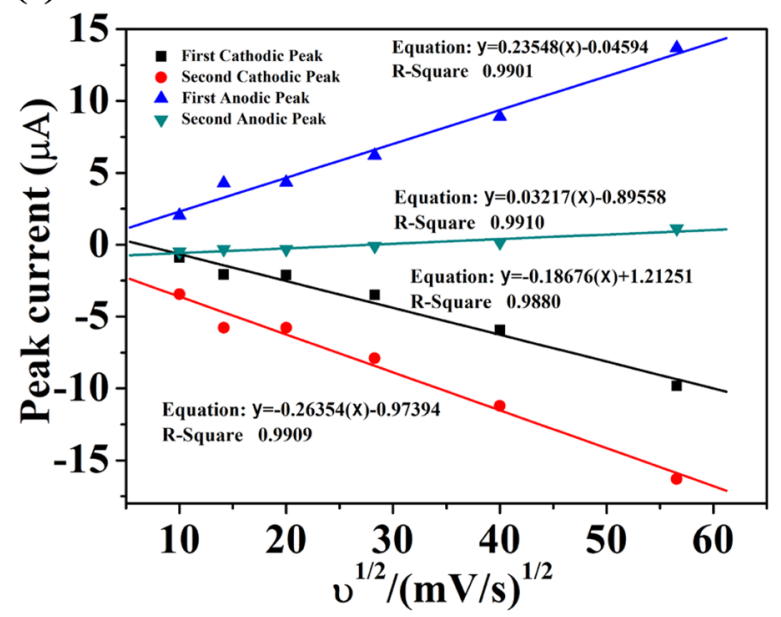

and complex 3 (f). Conditions: $0.10 \mathrm{M} \mathrm{n}-\mathrm{Bu}_{4} \mathrm{NClO}_{4} / \mathrm{CH}_{3} \mathrm{CN}$, glasscarbon working electrode $(\phi=1 \mathrm{~mm})$; Pt wire counter electrode; $\mathrm{Ag}$ / $\mathrm{AgNO}_{3}$ pseudoreference electrode; Fc internal standard $(*)$ 
(a)

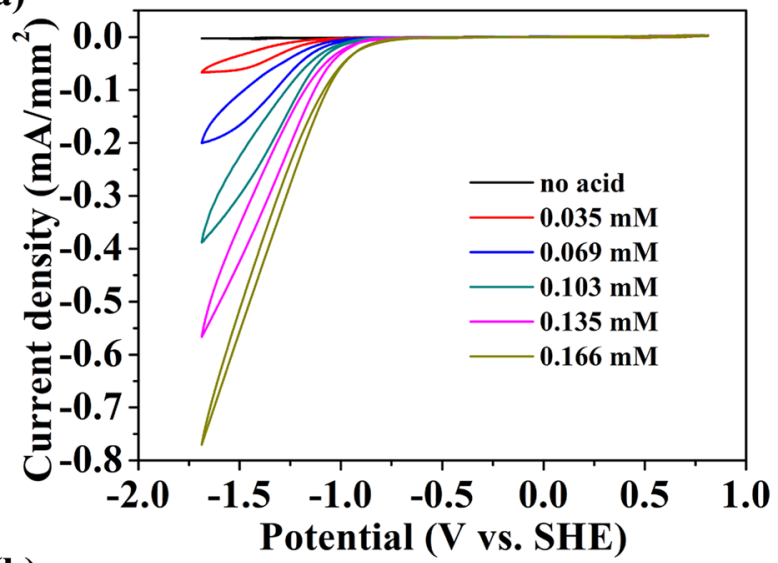

(b)

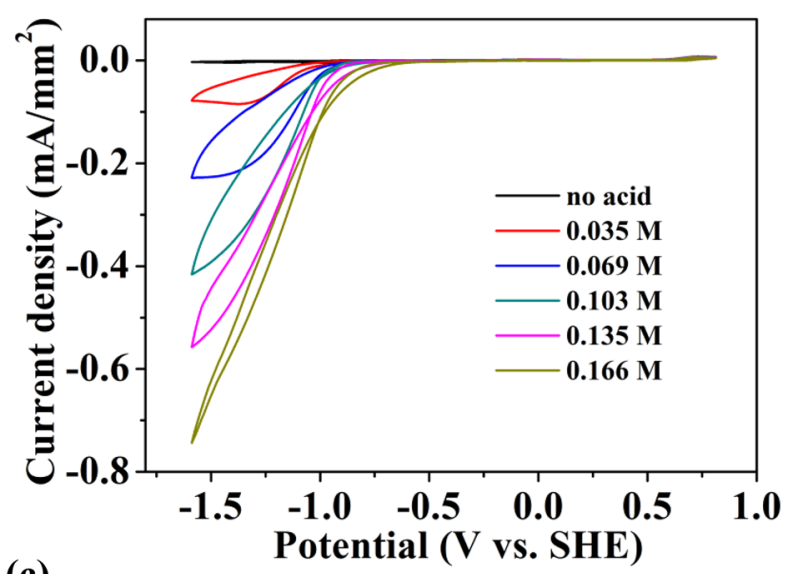

(c)

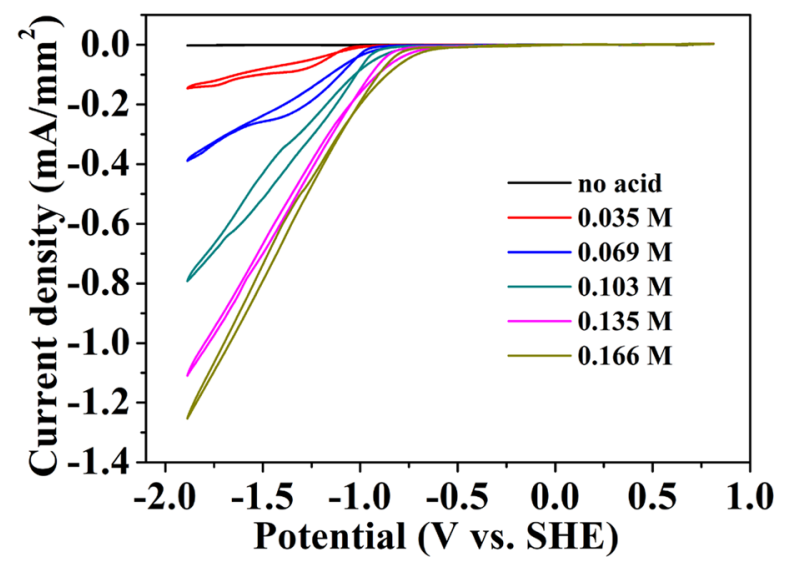

Fig. 5 Cyclic voltammograms of $0.5 \mathrm{mM}$ Complex 1 (a), Complex 2 (b), and Complex 3 (c) in $0.10 \mathrm{M} \mathrm{n}-\mathrm{Bu}_{4} \mathrm{NClO}_{4} / \mathrm{MeCN}$ with increasing $\mathrm{AcOH}$ concentration. Conditions: glass-carbon working electrode $(\phi=1 \mathrm{~mm})$; Pt wire counter electrode; $\mathrm{Ag} / \mathrm{AgNO}_{3}$ pseudoreference electrode; ferrocene as the internal standard, scan rate $0.1 \mathrm{~V} \mathrm{~s}^{-1}$

bulk electrolysis, 41.5, 52.1, and 60.3 Coulomb of charges are passed, and approximate amounts of 589.2, 699.3, and $794.1 \mu \mathrm{mol}$ of hydrogen are formed, corresponding to TONs of 1647.4, 1955.1, and 2220.2 and TOFs of 411.9, 488.8, and $555.1 \mathrm{~h}^{-1}$ (Table 2), respectively. While at the same condition without catalyst only $3.1 \mu \mathrm{mol}$ of hydrogen can be obtained.
No matter in homogeneous bulk electrolysis and heterogeneous bulk electrolysis, among three complex catalysts for HER, Complex 3 is the best one for hydrogen production, confirming that the ligand of tdas $^{2-}$ has the positive free energy for HER [16].

In addition, to further explore the activity and stabilization of three complex catalysts, $48 \mathrm{~h}$ of electrolysis were performed in three phosphate solutions. To maintain the liquid level in two-compartment electrolysis cell, the amount of produced hydrogen at the first hour and the last hour during electrolysis were measured (Fig. S14). The results show that 395.3, 409.1, and 466.0 Coulomb of chargers are passed for Complex 1, Complex 2, and Complex 3 containing electrolytes, respectively. After $48 \mathrm{~h}$ of electrolysis, the catalysts still keep a commendable hydrogen production activity, showing that the complex catalysts can maintain a certain stability under a long electrocatalysis and can perform a good hydrogen-evolving reaction.

\section{Effect of Proton on the Redox Potentials}

In order to study the effect of proton on three complex catalysts, the change of the UV-vis spectra in $\mathrm{MeCN}$ with increasing the concentration of acetic acid were investigated, as shown in Figs. S15, S16 and S17. It can be seen that when AcOH concentration is added from 0 up to $50 \mathrm{~L}(0.17 \mathrm{M})$, no obvious change of UV-vis spectra of the three $\mathrm{Ni}(\mathrm{II})$ complexes, showing that there is no protonation appearance on the complexes under the condition. It can also be seen from the CVs of three complexes in the solution with various concentrations of $\mathrm{AcOH}$, the first reduction Wave $\mathbf{1}$ and Wave $\mathbf{3}$ keep the same, the values of $E_{c a t / 2}$ from the second reduction wave of the three complexes positively shift quickly with increasing AcOH concentration, suggesting that it might be the protoncoupled electron transfer steps, in which the electrochemical reduction coupled with the proton adoption appears. The phosphate buffer solution with various $\mathrm{pH}(5.0-7.0)$ values were also used in bulk electro-catalysis. As shown in Fig. 9a-d, the amounts of hydrogen are measured at different $\mathrm{pH}$ values. At $\mathrm{pH}=5,6$, and 7, the values are 588.1, 485.3, and $298.2 \mu \mathrm{mol}$ for Complex 1; 699.5, 586.6, and $485.5 \mu \mathrm{mol}$ for Complex 2; and 794.8, 545.3, and $422.5 \mu \mathrm{mol}$ for Complex 3 . These results indicate that the amount of $\mathrm{H}_{2}$ is decreased with increasing $\mathrm{pH}$ value. Therefore, the proton concentration can strongly impact the HER through directly affect the reaction rate.

\section{Mechanism of the Electrocatalytic $\mathrm{H}_{2}$ Evolution}

Based on literature precedents $[13,51,52]$ and our results, the proposed catalytic cycle for hydrogen generation from aqueous solution mediated by three complex catalysts is shown in 
Fig. 6 Plots of $i_{c a t} / i_{p}$ vs concentration of $\mathrm{AcOH}$ for Complex

1, Complex 2 (a) and Complex 3 (b) in $0.10 \mathrm{M} \mathrm{n}-\mathrm{Bu}_{4} \mathrm{NClO}_{4} /$ $\mathrm{MeCN}$ with a scan rate of 0.1 $\mathrm{V} \mathrm{s}^{-1}$

Fig. 7 a The amounts of hydrogen evolution for $4 \mathrm{~h}$ of bulk electrolysis at $-0.99 \mathrm{~V}$ (versus $\mathrm{SHE}$ ) in an $\mathrm{MeCN}$ solution containing $\mathrm{n}-\mathrm{Bu}_{4} \mathrm{NClO}_{4}(0.1$ $\mathrm{M})$, acetic acid (0.2 M), Complex 1, Complex 2, Complex 3 $(0.05 \mathrm{mM})$, or without catalyst. Conditions: glass-carbon working electrode (geometric surface area $\left.=0.31 \mathrm{~cm}^{2}\right)$; Pt wire counter electrode; $\mathrm{Ag} / \mathrm{AgNO}_{3}$ pseudoreference electrode. $\mathbf{b}$

Time courses of the charge buildup for the bulk electrolysis

Fig. 8 a The amounts of hydrogen evolution for $4 \mathrm{~h}$ of bulk electrolysis at -0.49 $\mathrm{V}$ (versus SHE) in an phosphate buffer solution (pH 5.0) contaning Complex 1, Complex 2, Complex $3(0.05 \mathrm{mM})$, or without catalyst. Conditions: glass-carbon working electrode (geometric surface area $=0.31$ $\mathrm{cm}^{2}$ ); Pt wire counter electrode; $\mathrm{Ag} / \mathrm{AgCl}$ pseudoreference electrode. $\mathbf{b}$ Time courses of the charge buildup for the bulk electrolysis
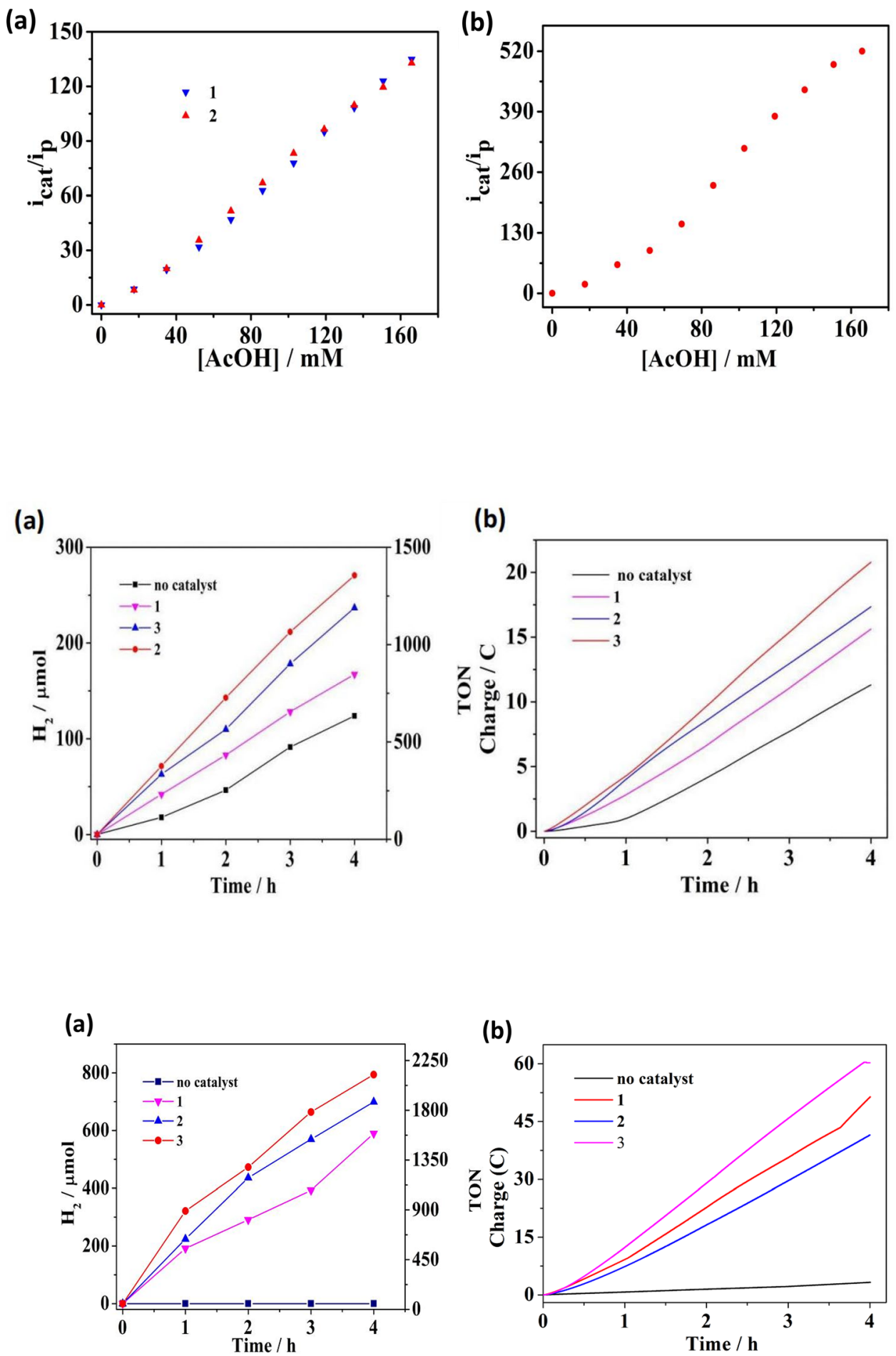
Table 2 Electrocatalytic $\mathrm{H}_{2}$ production with Complexes 1, 2, and 3 in phosphate buffer solution

\begin{tabular}{lllll}
\hline Complex & $\mathrm{H}_{2}(\mathrm{~mol})$ & $\mathrm{TON}^{\mathrm{a}}$ & $\mathrm{TOF}^{\mathrm{b}} \mathrm{h}^{-1}$ & $\mathrm{FE}(\%)$ \\
\hline $\mathbf{1}$ & 589.2 & 1647.4 & 411.9 & 91 \\
$\mathbf{2}$ & 699.3 & 1955.1 & 488.8 & 92 \\
$\mathbf{3}$ & 794.1 & 2220.2 & 555.1 & 92 \\
\hline
\end{tabular}

${ }^{\text {a }}$ The TON $\left(\left(\right.\right.$ moles $\left.\mathrm{H}_{2}\right) /($ moles catalyst $\left.)\right)$ in 4-h electrolysis

${ }^{\mathrm{b}}$ The TOF was the average of TON for $4 \mathrm{~h}$

(a)

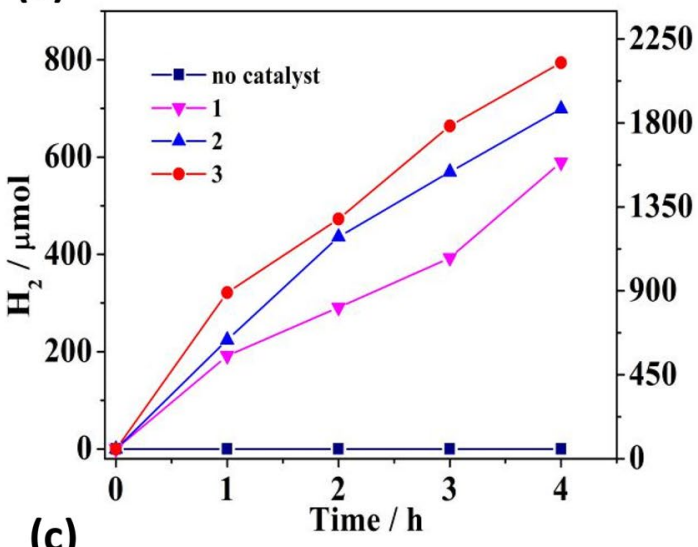

(c)

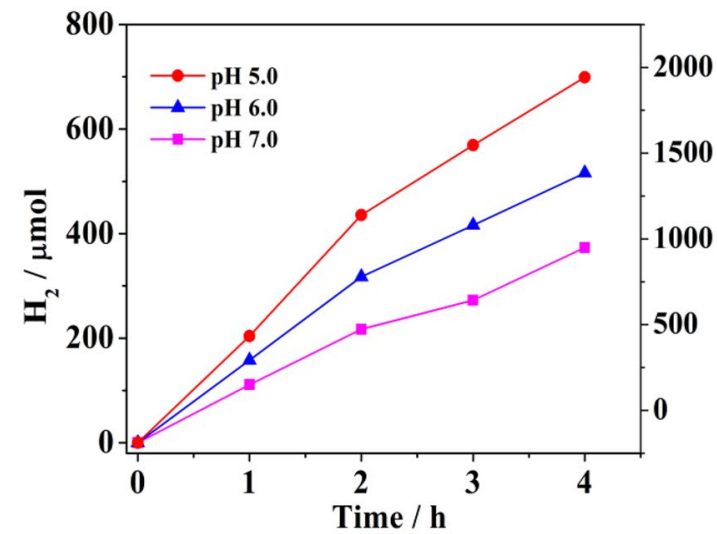

Fig. 9 a The amounts of hydrogen evolution for $4 \mathrm{~h}$ of bulk electrolysis at $-0.49 \mathrm{~V}$ (versus SHE) in an phosphate buffer solution containing Complex 1, Complex 2, Complex $3(0.05 \mathrm{mM})$, or without catalyst. Bulk electrolysis of various $\mathrm{pH}(5.0-7.0)$ in phosphate
Fig. 10. The $\mathrm{H}_{2}$ evolution process might be occurred based on proton-coupled electron transfer. For Complexes $\mathbf{1}$ and 3 , $\left[\mathrm{L}_{2} \mathrm{Ni}^{\mathrm{II}}\right]^{2-}$ is firstly reduced by two electrons to $\left[\mathrm{L}_{2} \mathrm{Ni}^{0}\right]^{4-}$, and then one proton is involved to form the intermediate $\left[\mathrm{L}_{2} \mathrm{Ni}^{\mathrm{I}}-\mathrm{H}\right]^{3-}$, which would further react with a proton to form hydrogen. For Complex 2, at first, $\left[\mathrm{L}_{2} \mathrm{Ni}^{\mathrm{II}}\right]^{2-}$ is converted to $\left[\mathrm{L}_{2} \mathrm{Ni}^{\mathrm{I}}\right]^{3-}$ by a one-electron reducing step, and then $\left[\mathrm{L}_{2} \mathrm{Ni}^{\mathrm{I}}\right]^{3-}$ accepts one proton to generate the intermediate $\left[\mathrm{L}_{2} \mathrm{Ni}^{\mathrm{II}}-\mathrm{H}\right]^{2-}$, and at the final stage, hydrogen is produced by obtaining a proton.

\section{(b)}

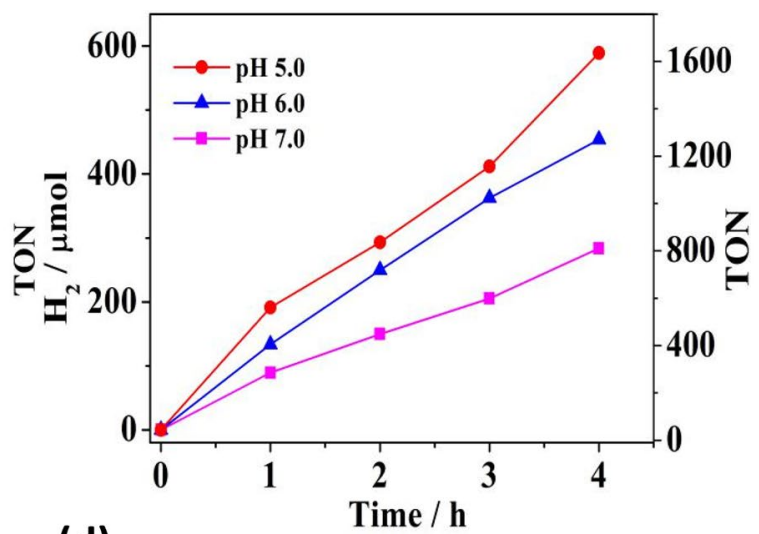

(d)

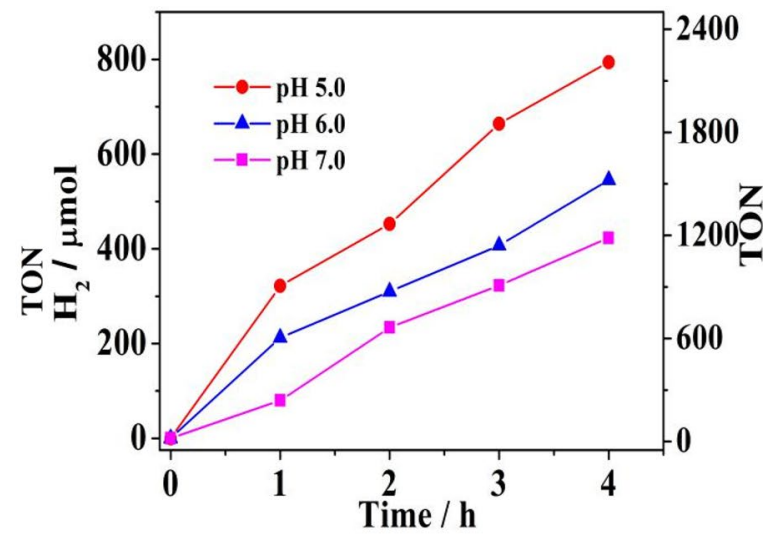

buffer solution with Complex 1 (b), Complex 2 (c), or Complex 3 (d). Conditions: glass-carbon working electrode (geometric surface area $=$ $0.31 \mathrm{~cm}^{2}$ ); Pt wire counter electrode; $\mathrm{Ag} / \mathrm{AgCl}$ pseudoreference electrode 


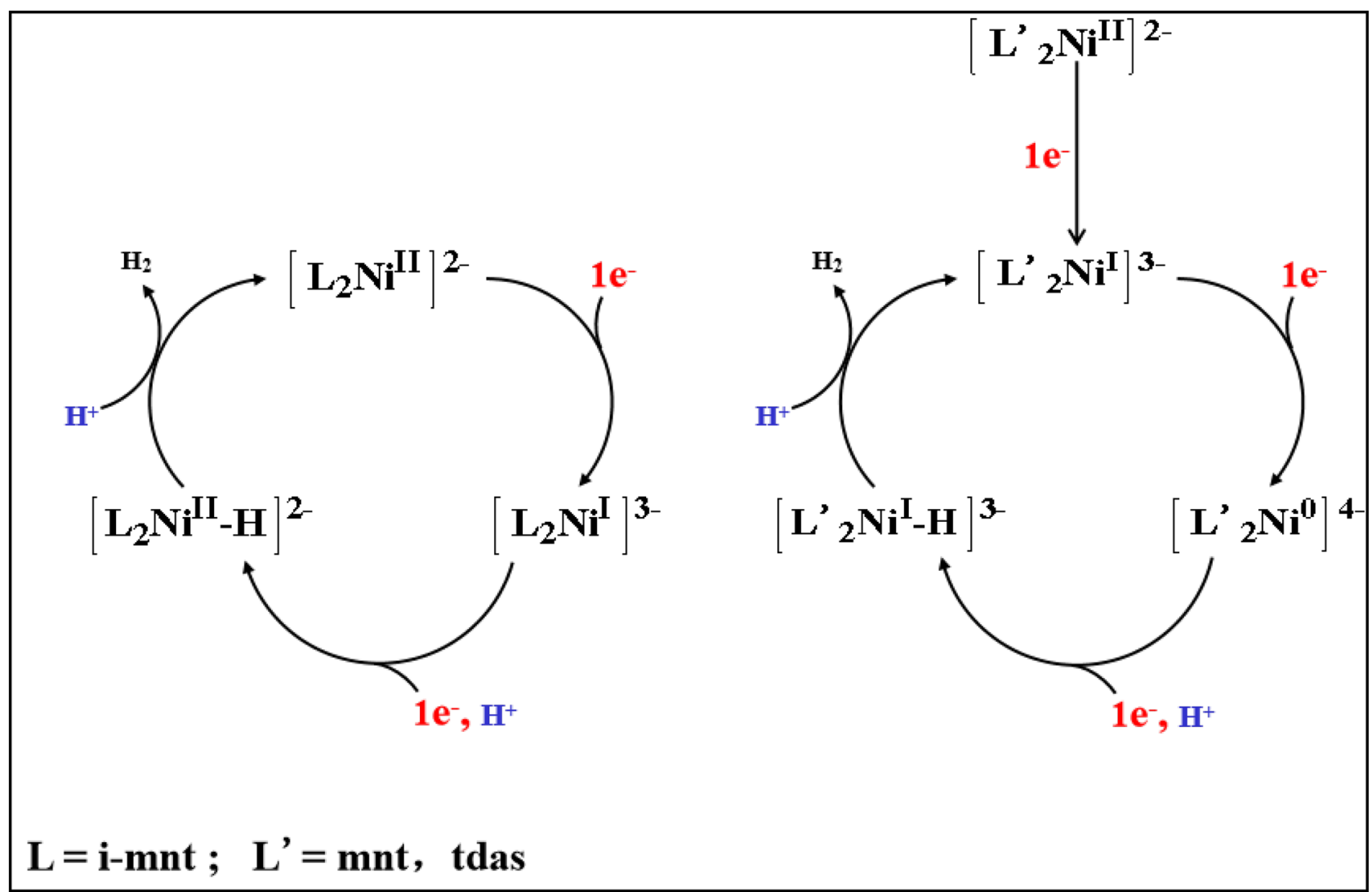

Fig. 10 Proposed mechanism of electrocatalytic hydrogen production with Complex 1, Complex 2, and Complex 3

\section{Conclusions}

In conclusion, three earth-abundant $\mathrm{Ni}$-dithiolene complexes are synthesized and studied for catalysts of hydrogen evolution reaction (HER) for hydrogen production. These three complex catalysts possess good electro-catalytic activity and long-term electrocatalytic stability in acetonitrile and phosphate buffer solutions. The present work reveals that the dithiolene ligands play a vital role in catalytic HER and provides important an insight into new design and synthesis of high efficient metal molecular electrocatalysts for hydrogen production.

Supplementary Information The online version contains supplementary material available at https://doi.org/10.1007/s12678-022-00708-8.

Funding This work was supported by the Science and Technology Project (No. 2016A010103025) from Guangdong Science and Technology Department and the National Science Foundation of China (No. 20701045).

\section{Declarations}

Accession Codes CCDC-1915576, CCDC-1915577, and CCDC698890 contain the supplementary crystallographic data for $\mathbf{1}-\mathbf{3}$. These data can be obtained free of charge from The Cambridge Crystallographic Data Centre via www.ccdc.cam.ac.uk/data_request/cif.
Conflict of Interest The authors declare no competing interests.

Open Access This article is licensed under a Creative Commons Attribution 4.0 International License, which permits use, sharing, adaptation, distribution and reproduction in any medium or format, as long as you give appropriate credit to the original author(s) and the source, provide a link to the Creative Commons licence, and indicate if changes were made. The images or other third party material in this article are included in the article's Creative Commons licence, unless indicated otherwise in a credit line to the material. If material is not included in the article's Creative Commons licence and your intended use is not permitted by statutory regulation or exceeds the permitted use, you will need to obtain permission directly from the copyright holder. To view a copy of this licence, visit http://creativecommons.org/licenses/by/4.0/.

\section{References}

1. L.M. Dai, Y.H. Xue, L.T. Qu, H.J. Choi, J.B. Baek, Metal-free catalysts for oxygen reduction reaction. Chem. Rev. 115, 4823-4892 (2015)

2. H. Chen, Y. Gao, Z.K. Lu, L. Ye, L.C. Sun, Copper oxide film in-situ electrodeposited from $\mathrm{Cu}$ (II) complex as highly efficient catalyst for water oxidation. Electrochim. Acta 230, 501-507 (2017)

3. J.Q. Lin, P. Kang, X.M. Liang, B.C. Ma, Y. Ding, Homogeneous electrocatalytic water oxidation catalyzed by a mononuclear nickel complex. Electrochim. Acta 258, 353-359 (2017) 
4. L. Mond, C.V. Langer, A new form of gas battery. Proc. R. Soc. 46, 280-285 (1890)

5. M.D. Sampson, C.P. Kubiak, Electrocatalytic dihydrogen production by an earth-abundant manganese bipyridine catalyst. Inorg. Chem. 54, 6674-6676 (2015)

6. B, Kandemir, L, Kubie, Y.X. Guo, B, Sheldon, K.L. Bren, Hydrogen evolution from water under aerobic conditions catalyzed by a cobalt ATCUN metallopeptide, Inorg. Chem. 55,1355-1357 (2016)

7. J.G. Kleingardner, B. Kandemir, K.L. Bren, Hydrogen evolution from neutral water under aerobic conditions catalyzed by cobalt microperoxidase-11. J. Am. Chem. Soc. 136, 4-7 (2014)

8. M.A. Khan, H.B. Zhao, W.W. Zou, Z. Chen, W.J. Cao, J.H. Fang, J.Q. Xu, L. Zhang, J.J. Zhang, Recent progresses in electrocatalysts for water electrolysis. Electro. Ener. Rev. 1, 483-530 (2018)

9. J.J. Lu, S.B. Yin, P.K. Shen, Carbon-encapsulated electrocatalysts for the hydrogen evolution reaction. Electro. Ener. Rev. 2, 105-127 (2019)

10. Z.Q. Wang, L.Z. Tang, Y.X. Zhang, S.Z. Zhan, J.S. Ye, Electrochemical-driven water splitting catalyzed by a watersoluble cobalt(II) complex supported by N, N'-bis(2'pyridinecarboxamide)-1,2-benzene with high turnover frequency. J. Power Sources 287, 50-57 (2015)

11. J.A. Turner, Sustainable hydrogen production. Science 305, 972974 (2004)

12. G.W. Crabtree, M.S. Dresselhaus, The hydrogen fuel alternative. MRS Bull. 33, 421-428 (2008)

13. C. Tsay, J.Y. Yang, Electrocatalytic hydrogen evolution under acidic aqueous conditions and mechanistic studies of a highly stable molecular catalyst. J. Am. Chem. Soc. 138, 14174-14177 (2016)

14. R. Tatematsu, T. Inomata, T. Ozawa, H, Masuda, Electrocatalytic hydrogen production by a nickel (II) complex with a phosphinopyridyl ligand. Angew. Chem. Int. Ed. 55, 5247-5250 (2016)

15. M.L. Helm, M.P. Stewart, R.M. Bullock, M.R. DuBois, D.L. DuBois, A synthetic nickel electrocatalyst with a turnover frequency above $100,000 \mathrm{~s}^{-1}$ for $\mathrm{H}_{2}$ production. Science 333, 863$866(2011)$

16. S. Wiese, U.J. Kilgore, D.L. DuBois, M. Bullock, $\left[\mathrm{Ni}\left(\mathrm{P}^{\mathrm{Me}}{ }_{2} \mathrm{~N}^{\mathrm{Ph}}\right)_{2}\right]$ $\left(\mathrm{BF}_{4}\right)_{2}$ as an electrocatalyst for $\mathrm{H}_{2}$ production. ACS Catal. 2, 720 727 (2012)

17. P.A. Jacques, V. Artero, J. Pécaut, M. Fontecave, Cobalt and nickel diimine-dioxime complexes as molecular electrocatalysts for hydrogen evolution with low overvoltages. PNAS. 106, 2062720632 (2009)

18. J.L. Dempsey, B.S. Brunschwig, J.R. Winkler, H.B. Gray, Hydrogen evolution catalyzed by cobaloximes. Acc. Chem. Res. 42, 1995-2004 (2009)

19. X. Hu, B.S. Brunschwig, J.C. Peters, Electrocatalytic hydrogen evolution at low overpotentials by cobalt macrocyclic glyoxime and tetraimine complexes. J. Am. Chem. Soc. 129, 8988-8998 (2007)

20. V. Artero, M. Fontecave, Some general principles for designing electrocatalysts with hydrogenase activity. Coord. Chem. Rev. 249, 1518-1535 (2005)

21. F. Gloaguen, T.B. Rauchfuss, Small molecule mimics of hydrogenases: Hydrides and redox. Chem. Soc. Rev. 38, 100-108 (2009)

22. S.K. Ghumaan, L. Schwartz, R. Lomoth, M. Stein, S. Ott, Catalytic hydrogen evolution from mononuclear iron(II) carbonyl complexes as minimal functional models of the [FeFe] hydrogenase active site. Angew. Chem. Int. Ed. 49, 8033-8036 (2010)

23. T.B. Liu, M.Y. Darensbourg, A mixed-valent, Fe(II)Fe(I), diiron complex reproduces the unique rotated state of the $[\mathrm{FeFe}]$ hydrogenase active site. J. Am. Chem. Soc. 129, 7008-7009 (2007)

24. H.R. Zuo, Q. Huang, C.Y. Huang, D.H. Huang, Y. Hou, L.M. Yang, C.L. Ni, Q.J. Meng, Unusual spin gap transition observed in two new molecular magnets based on $\left[\mathrm{Ni}(\mathrm{mnt})^{2}\right]^{-}$monoanion $\left(\mathrm{mnt}^{2-}=\right.$ maleonitriledithiolate). J. Solid. State. Chem. 182, 147-152 (2009)

25. Y. Hou, W.T. Yin, X.D. Xie, X. Chen, J.R. Zhou, H.R. Zuo, Q. Huang, L.M. Yang, C.L. Ni, X.L. Hu, 2D crystal structure, magnetic behavior and theoretic analysis of two new molecular solids based on $\mathrm{Ni}$ (maleonitriledithiolate) $)_{2}$ monoanion with substituted 2-aminopyridinium. Inorg. Chim. Acta. 363, 424-429 (2010)

26. H.Q. Ye, Q.Y. Guan, S. Han, X.J. Wang, R.K. Huang, W.Q. Chen, J.R. Zhou, L.M. Yang, C.L. Ni, Two molecular metals with one-dimensional non-uniform magnetic chain of bis(maleonitriledithiolate)nickel(III) monoanion: syntheses, structures and magnetic properties. Synth. Met. 188, 116-123 (2014)

27. W.Q. Chen, M.H. Feng, D.D. Zhou, Y.Q. Peng, S. Han, X.P. Liu, L.M. Yang, J.R. Zhou, C.L. Ni, Two tetrachlorocobaltate(II) salts with substituted benzyl triphenylphosphonium: syntheses, crystal structures, weak interactions, and magnetic properties. Synth. React. Inorg. M 42, 811-817 (2012)

28. W.Q. Chen, L.J. Su, X.Q. Cai, J.J. Yang, Y.L. Qian, X.P. Liu, L.M. Yang, J.R. Zhou, C.L. Ni, Syntheses, crystal structures, and magnetic properties of two meta-substituted benzyl triphenylphosphinium tetra(isothiocyanate)cobaltate(II) complexes. Synth. React. Inorg. M 44, 980-985 (2014)

29. C.N. Lin, D. Xue, Y.H. Zhou, S.Z. Zhan, C.L. Ni, The effect of oxidation state of metal on hydrogen production electro-catalyzed by nickel complexes supported by maleonitriledithiolate ligand. J. Electroanal. Chem. 785, 58-64 (2017)

30. Y. Liu, L.Z. Fu, L.M. Yang, X.P. Liu, S.Z. Zhan, C.L. Ni, The impact of modifying the ligands on hydrogen productionelectrocatalyzed by meso-tetra-p-X-phenylporphin cobaltcomplexes, CoT(X)PP. J. Mol. Catal. A-Chem. 417, 101-106 (2016)

31. A. Zarkadoulas, M.J. Field, V. Artero, C.A. Mitsopoulou, Protonreduction reaction catalyzed by homoleptic nickel-bis-1,2dithiolate complexes: experimental and theoretical mechanistic investigations. ChemCatChem. 9, 2308-2317 (2017)

32. M.G. Mingot, J.P. Porcher, T.K. Todorova, T. Fogeron, C.M. Draznieks, Y. Li, M. Fontecave, Bioinspired tungsten dithiolene catalysts for hydrogen evolution: a combined electrochemical, photochemical, and computational study. J. Phys. Chem. B 119, 13524-13533 (2015)

33. C.S. Letko, J.A. Panetier, M.H. Gordon, T.D. Tilley, Mechanism of the electrocatalytic reduction of protons with diaryldithiolene cobalt complexes. J. Am. Chem. Soc. 136, 9364-9376 (2014)

34. W.R. McNamara, Z.J. Han, P.J. Alperin, W.W. Brennessel, P.L. Holland, R. Eisenberg, Mechanism of the electrocatalytic reduction of protons with diaryldithiolene cobalt complexes. J. Am. Chem. Soc. 133, 15368-15371 (2011)

35. W.R. McNamara, Z.J. Han, C.J. Yin, W.W. Brennessel, P.L. Holland, R. Eisenberg, Cobalt-dithiolene complexes for the photocatalytic and electrocatalytic reduction of protons in aqueous solutions. PNAS. 109, 15594-15599 (2012)

36. A. Davison, R.H. Holm, Metal complexes derived from cis-1, 2-dicyano-1,2-ethylenedithiolate and bis(trifluoromethyl)1,2-dithiete. Inorg. Synth. 10, 8-26 (1967)

37. S.G. Liu, Y.Q. Liu, Y.F. Li, D.B. Zhu, Crystal structure, spectral and electrochemical properties of $[\mathrm{TBA}]_{2}\left[\mathrm{Ni}(\mathrm{i}-\mathrm{MNT})_{2}\right]$, [TBA] $\left[\mathrm{Ni}(\mathrm{i}-\mathrm{MNT})_{2}\right],[\mathrm{TBA}]_{2}\left[\mathrm{Ni}(\mathrm{i}-\mathrm{MNS})_{2}\right]$ and related bis $(1,2-$ dithiolene) metal complexes. Synth. Met. 8, 131-140 (1997)

38. O.A. Dyachenko, S.V. Konovalikhin, A.I. Kotov, G.V. Shilov, E.B. Yagubskii, C. Faulmann, P. Cassoux, The synthesis and first X-ray structures of nickel complexes of 1,2,5-thiadiazole-3,4-dithiolate, J. Am. Chem. Soc. 0, 508-510 (1993)

39. S.B. Bularevicha, D.V. Brena, D.Y. Movshovic, P. Finocchiarob, S. Failla, Conformational investigation of N-aralkylpyridinium ions by Cotton-Mouten effect method. J. Mol. Struct. 317, 147155 (1994) 
40. H.R. Zuo, Q. Huang, Y. Zheng, X.P. Liu, L.L. Yu, J.R. Zhou, C.L. $\mathrm{Ni}$, Two new salts based on bis(1,2,5-thiadiazole-3,4-dithiolate)nickelate anion with benzylpyridinium derivatives: syntheses, crystal structures and properties. Synth. React. Inorg. M 40, 12-18 (2010)

41. SMART and SAINT, Siemens analytical X-ray instrument, Inc: Madison WI (1996)

42. G.M. Sheldrick, SHELXS97. A program for crystal structure solution, university of Göttingen: Göttingen Germany (1997)

43. G.M. Sheldrick, A short history of SHELX. Acta. Crystallogr. A: Found Crystallogr. 64, 112-122 (2008)

44. G.M. Sheldrick, Crystal structure refinement with SHELXL. Acta Crystallogr Sect. A: Found. Adv. 71, 3-8 (2015)

45. V. Fourmond, P.A. Jacques, M. Fontecave, V. Artero, $\mathrm{H}_{2}$ evolution and molecular electrocatalysts: determination of overpotentials and effect of homoconjugation. Inorg. Chem. 49, 10338-10347 (2010)

46. F. Eckert, I. Leito, I. Kaljurand, A. Kütt, A. Klamt, M. Diedenhofen, Prediction of acidity in acetonitrile solution with COSMO-RS. J. Comput. Chem. 30, 799-810 (2009)

47. R.S. Nicholson, I. Shain, Theory and application of cyclic voltammetry for measurement of electrode reaction kinetics. Anal. Chem. 36, 706-711 (1964)
48. J.M. Saveant, E. Vianello, Potential-sweep chronoamperometry: kinetic currents for first-order chemical reaction parallel to electron-transfer process (catalytic currents). Electrochim. Acta. 10, 905-920 (1965)

49. S.N. Richard, I. Shain, Experimental verification of an ECE mechanism for the reduction of p-nitrosophenol, using stationary electrode polarography. Anal. Chem. 37, 190-195 (1965)

50. R. Tatematsu, T. Inomata, T. Ozawa, H. Masuda, Electrocatalytic hydrogen production by a nickel(II) complex with a phosphinopyridyl ligand. Angew. Chem. Int. Ed. 55, 5247-5250 (2016)

51. V. Artero, J.M. Saveant, Toward the rational benchmarking of homogeneous $\mathrm{H}_{2}$-evolving catalysts. Energy Environ. Sci. 7, 3808-3814 (2014)

52. D.C. Hong, Y. Tsukakoshi, H. Kotani, T. Ishizuka, K. Ohkubo, Y. Shiota, K. Yoshizawa, S. Fukuzumi, T. Kojima, Mechanistic insights into homogeneous electrocatalytic and photocatalytic hydrogen evolution catalyzed by high-spin $\mathrm{Ni}(\mathrm{II})$ complexes with $\mathrm{S}_{2} \mathrm{~N}_{2}$-type tetradentate ligands. Inorg. Chem. 57, 7180-190 (2018)

Publisher's Note Springer Nature remains neutral with regard to jurisdictional claims in published maps and institutional affiliations. 